languages, since language deficiencies frequently prevented full benefit from fellowships. The paper by Dr. M. A. Garrido Malo, dean of the Science Faculty in San Marcos University, Lima, was on a closely allied subject-exchange of scientists between Latin-American countries. Unesco was asked to publish its Boletin with greater frequency, so that news of courses, special facilities, visits of foreign scientists, etc., might be more rapidly disseminated, and all laboratories were exhorted to use to the utmost the facilitios offered.

The subject of scientific documentation in Latin America was introduced by Dr. Manuel Sadosky, vice-dean of the Science Faculty in the University of Buenos Aires. A lengthy discussion led to a series of recommendations : that Unesco should make a survey of scientific journals in Latin America, with the object of formulating a plan for rationalizing them; that the Mexican Scientific Documentation Centre should make its services more easily available to scientists in other countries; that more national scientific documentation contres should be established, that Governments should grant free postal services to scientific journals; and that financial help might be given to a select number of journals.

The final subject on the agenda was a review of Unesco's science programmes, particularly that of the Latin American Science Co-operation Office in Montevideo. Dr. Establier described proposals to be debated at the general conference of the Organization held in Paris in November, and also outlined a series of long-term projects which might be undertaken by the Montevideo office. Among these was one for an International Andean Year. during which teams of specialists in differont fields would attack the problems of this vast mountain chain which so profoundly affects living conditions in those countries through whose territories it runs. Another proposal was for a full-scale operation towards rationalizing scientific journals. A third would deal with the problems of the unproductive areas of the seas, lakes and rivers of the continent. At the end of this discussion Dr. Establier received the warm congratulations of the meeting, both for the way he has directed Unesco's science activities in Latin America, and for the organization of the meeting.
B. A. Houssay

\title{
INTERNATIONAL OPERATIONAL RESEARCH
}

$\mathrm{F}^{\mathrm{r}}$ ROM its War-time start in Britain, operational research has become an international movement. The first conference on this basis was held three years ago at Oxford. It led to the establishment of the International Federation of Operational Research Societies, of which the chief architect was Sir Charles Goodeve, who was elected its first general secretary. Under his guidance the Federation continues to expand. Great Britain has acted as the Federation's first 'foster' society, an office which shortly passes to America ; and France was designated 'host' society for the second of the triennial conferences, called at Aix-en-Provence during September 5-9. The Société Française de Recherche Opérationnelle has dischargod its duties with grace and efficiency, at a conference presided over by its own president, Prof. G. T. Guilbaud.

The Second International Conference on Operational Research had the object of surveying the whole scene, and its organizers limited the attendance to 350 delegates. Representation at the national level was strictly allocated according to the sizes of national societies, who themselves had the invidious task of selecting their delegations from long lists of applicants. The programme was determined in outline by a committee which appointed leading workers in this field as sponsors of more than twenty sessions ; each sponsor was responsible for designing and presenting his own session, for inviting some papers, for selecting others from among those submitted freely, and for taking the chair at his session at Aix-en-Provence. These arrangements led to a more tightly controlled conference than is customary at this level, and were intended to produce a coherent pattern, high-quality material, and authoritative discussion.

Delegates arrived from no loss than twenty-three countries; and although two-thirds of them were drawn from America, Britain and France, there was plenty of evidence that significant operational research efforts have been mounted in at least a dozen more countries. The extent of the applications of operational research to-day might have surprised those who first embarked on the attempt to apply the methods of science to the strategic problems of war. But there are strategic problems in all managerial situations, and eighty papers presented at Aix-enProvence attest to the fact that operational research has by now penotrated into the intricacies of most of them.

The conference oponed with a plonary session dealing with the methodological aspects of operational research. Whispers were heard complaining that once again the subject had succumbed to mere introspection, to a self-conscious preoccupation with its own anatomy. Most scientists in the field of operational research would agree, however, that a subject devoted to scientific investigation of the methods of management has something to gain from the examination of its own. Thus it proved. The sossion brought out clearly the fact that the goals of an organization are various and not necessarily consistent, that they are constantly changing, and that they reflect a process of learning to survive by adaptation. It follows that crude statements of aim, such as 'maximum profit', which have often been naïvoly emulated by equally crude scientific models, are inadequate. There are always ways of estimating and comparing organizational efficiency, but they require experimentation on possible models and not merely experimentation within somo plausible model. The sensitivity of a top-level decision to explicit assumptions about likoly circumstances is itsolf an object of study; but its sensitivity to implicit assumptions about goals is still more important. For this reason the model of an adaptive organism adjusting itself to its environment is valuable, and much was said about attempts to use sciontific descriptions of biological learning and 
goal-seeking processes as models of business behaviour.

The first group of parallel sessions then set out to discuss two general problems and five arees of application. Six papers were presented dealing with new mathematical methods: thoy concerned especially the use of the theory of graphs in studying supply networks, and various treatments of the problems of sequential decision. Another group of papers dealt briefly with the question of controlling production, but without much originality. The areas of application were: transport, oil, power, steel and local government. Examples of transport operations by road, rail and air were given in which operational research had solved the strategic problems of scheduling fleets, and of choosing between alternative policies, for example, in overhaul, cargo carried and design. The oil industry put forward studies of the flow of traffic and the problems of stock-holding, and of the selection of investments. There were three papers in the session on power dealing with the operation of nuclear reactors, and studies were also presented of the central planning of an atomic energy industry and of an electricity distribution system. From the steel industry there were discussions of the control of spare parts and of the unloading of ore, and a study of track times. The local government session was devoted to city and land-use planning, and included a consideration of a city as a teleological mechanism generating its objectives intrinsically.

The formal sessions were broken up by a series of discussion groups. These were often extremely spirited conversations. They dealt, for example, with the organization of operational research, with its future needs, and with education-the latter subject leading to a considerable clash about the role of the universities and possible syllabuses. One group discussed economic decisions that could involve loss of life, and two more the allied techniques of operational gaming and of simulation. There was a meeting on operational research for under-developed countries. But perhaps the most remarkable session of all dealt with operational research at the topdecision-making level in industry. This involved some of the most forceful interchanges of the whole conference, and continued all day-although it was billed to last for the morning only. The discussion was too frank, too fast, and too heated ever to reach the printed proceedings: an added reason for the agreement of the main protagonists that this day alone had been worth the journey to France.

At this point, the second plenary session was held, to consider the relationship between operational research and computers. It was held that the existence of these machines, considered properly as logical engines rather than as calculators, had enabled operational research to forge new tools. Those discussed were a computer language for the automatic programming of simulations, which had quartered the time required to prepare an intricate programme, and a computer analysis of the field of heuristic decision processes. Secondly, however, computer applications themselves received benefit from operational research assistance. In this area, a mathematical model was presented for the optimal storage and retrieval of information, and an operational research survey was made of the factors involved in the introduction of on-line computers for controlling production.
The second series of parallel sessions included two general problem areas, those of inventory control theory and mathematical programming, and descriptions of operational research in three applied fields; mining, war and national government. Inventory theory is by now an extensively explored topie, but seven more contributions were made dealing with particular aspects of the problem. There were nine contributions also to the subject which began as linear programming, but which has long since been extended to such cases as the linear programme under uncertainty, various non-linear models, and quadratic programming-all discussed here. In the mining session, a general account of operational research at the National Coal Board in Britain was presented, as well as papers on the determination of optimal mining limits and the study of pit haulage. The presentation of military applications was necessarily restricted, but the relevance of the theory of games was discussed, as well as problems of communications and stock. holding policy. The growing effort in operational research at the national level was well expressed in various papers dealing with the whole economic system of a country, with national planning in India, with the co-ordination of investment in transport, and with social decision-making.

The third and last plenary session was concerned with human factors. Hospitals were considered as viable organisms, according to an adaptive model reminiscent of the methodological talk at the beginning of the week, and there were other papers on the human element in decision systems. A doleful note was sounded at the end of a strenuous conference by the report of some interesting research into the accept. ance of solutions. Teams involved in business gaming were presented with the mathematically optimal strategy for their game after they had become implicated in the play; but in no case could any means be found by which they could be persuaded to use it.

The conference was closed with an address by $\mathrm{Sir}^{*}$ Charles Goodeve, who characteristically eschewed the usual valedictory platitudes. Instead, he issued a considerable challenge to the movement to play a bigger part in the social field, by bringing operational research to bear on the problem of evaluating alternative policies by developing a measure for human happiness. His address is reported in extenso elsewhere ${ }^{1}$, and it will be interesting to see what fruit it has borne when the Third International Conference on Operational Research meets in Oslo in 1963, when the Norwegian society is expected to be host.

The proceedings reported here were set in the familiar context of receptions, tours, committee meetings, and arbitrarily arranged discussion groups - some of which lasted until dawn. Enthusiasm was a keynote of the assembly, as befits a young endeavour, and it was quite evident that much important operational research is being done that does not reach print. The first reason for this is an occupational hazard of the work : the advisors of management cannot readily air the secrets of institutional policy in public. But the second reason seems to be the convention that reports of operational research ought to include wads of respectable mathematics. whereas in real life the mathematics involved in operational research are often trivial.

Much was said at Aix-en-Provence publicly to acknowledge this fact, and to emphasize again the approaches for which operational research has always stood: scientific method, with its insistence on 
measurement, experimentation and logical inquiry ; interdisciplinary collaboration; above all, the seeking of usable insights rather than the production of abstract and possibly sterile formulæ. This reaffirmation should do something to increase the supply of good literature on operational research. It will certainly encourage those whose intentions are concentrated whole-heartedly on the essentially practical task of helping policy-makers reduce the influence of chance on the outcomes of their decisions.

STAFFORD BeER

\section{BIOLOGICAL STRUCTURE AND FUNCTION}

$\mathrm{I}^{\mathrm{N}}$ 1956, the International Union of Biological Sciences decided to set up a Biochemistry Section Committee which would be a co-ordinating committee between itself and the International Union of Biochemistry. One of the main functions of this Committee is to make recommendations to both Unions for international symposia, embracing subjects in which both biochemistry and the biological sciences are combining to produce a rapidly expanding sphere of knowledge; on this basis the subject "Biological Structure and Function" was chosen for the first joint symposium which was held at the Wenner-Grens Institute, Stockholm, during September 12-17. About 150 scientists attended the symposium, at which 72 members from 11 different countries presented invited papers to the seven sections of the symposium.

The first section was on macromolecular structure and function (chairman, A. Tiselius). Dr. J. C. Kendrew (Cambridge) described with great clarity the work which he has carried out on the elucidation of the structure of myoglobin, and Dr. P.A. Albertsson (Uppsala) discussed a now technique for separating macromolecules by partitioning them in aqueous two-phase systems containing polymers such as dextran and polyethylene glycol. This method has great possibilities in, for example, purifying viruses and separating different sized fragments of disintegrated mitochondria and chloroplasts. The second day, devoted to the subject of microsomes and protein synthesis, was memorable for a masterly discussion of the endoplasmic reticulum by the chairman, Dr. K. R. Porter (New York), which culminated in a series of electron micrographs which clearly demonstrated the existence of this structure in plant cells. In the more biochemical section the emphasis was on the role of ribonucleoprotein particles in protein synthesis.

Mitochondrial structure and function were discussed on the third day (chairman, O. Lindberg). At the moment, two subjects appear to polarize the interest of the various investigators studying the relationship between mitochondrial structure and function. One is the phenomenon of mitochondrial swelling. It seems, however, that different lines of approach are being followed by various laboratories. On one hand, swelling and shrinking are related to the transition of mitochondria from one to another well-defined functional state, for example, from a state of full respiration where the mitochondria are found to shrink, to a state in which the respiration is limited by the absence of phosphate acceptor and where the mitochondria ere inclined to swell. On the other hand, mitochondrial swelling is considered to be the result of a more complete change of the normal structure with a loss of most of the mitochondrial functions; the inhibition of the swelling by different agents or the reverse of swelling by way of a 'contraction' of the swollen mitochondria are followed as means to define the physiological implications of the phenomenon. The other topic, to which numerous papers were devoted, was the mechanism of electron transport and phosphorylation in the diphosphopyridine nucleotide-flavin region of the respiratory chain. The interest in this point was raised both because of the finding that in the presence of flavo-substrates a reversal of electron transfer could take place by way of reactions requiring high-energy phosphate, and because of the suggestion that this phenomenon could be related to an adenosine triphosphate activation of succinate oxidation, which on the other hand is not inhibited by uncoupling agents. It seems that work on these two reactions may provide a good deal of information on the question of the synthesis and utilization of the high-energy compounds during the operation, both in the forward and backward directions, of the terminal part of the respiratory chain.

In the morning session on chloroplast and chromatophore structure and function (chairman, T. W. Goodwin), electron micrographs of chrometophores isolated from both purple and green photosynthetic bacteria were shown by Drs. A. W. Frenkel (Minneapolis) and J. A. Bergeron (Upton, N.Y.), and Dr. M. D. Kamen (Waltham) speculated ingeniously on the primary act of photosynthesis. Later in the day Dr. D. I. Arnon (Berkeley) described his latest investigations on photosynthesis in cell-free systems of Chromatium and Dr. Birgit Vennesland (Chicago) gave her views on photophosphorylation with particular reference to the possible role of a 'nascent formate' intermediate, recently postulated by Warburg. The developmental physiologists discussed intact cellular structure and function on the morning of the fifth day, under the chairmanship of Prof. J. Runnström. The topies discussed ranged from 'mitosis', when Dr. D. Mazia. described it in terms of a multitude of individual reactions co-ordinated into a fixed time pattern, to electron microscopy studies on ciliary and flagellar movements (B. Afzelius).

In the afternoon an important session on polysaccharides (chairman, G. Blix) included lectures by Dr. S. Hestrin (Jerusalem) on "The Growth of Saccharide Macromolecules" and by Dr. A. Dorfman (Chicago) on "The Acid Mucopolysaccharides of Connective Tissues", and concluded with another important paper on technique from Prof. Tiselius's laboratory, when Dr. P. Flodin described the gel-filtration method for separation of oligosaccharides.

The final session on specific membrane transport and its adaptation (chairman, B. D. Davis) produced further lively discussion, and the closing half-hour 